\title{
POLÍTICA DE FORMAÇÃO E EDUCAÇÃO PERMANENTE EM SAÚDE NO BRASIL: BASES LEGAIS E REFERÊNCIAS TEÓRICAS
}

\author{
CONTINUING TRAINING AND EDUCATION IN HEALTH POLICY IN BRAZIL: LEGAL BASIS AND \\ THEORETICAL REFERENCESS
}

\section{POLÍTICA DE FORMACIÓN Y EDUCACIÓN PERMANENTE EN SALUD EN BRASIL: BASES LEGALES Y REFERENCIAS TEÓRICAS}

\author{
Renata Lúcia Gigante ${ }^{1}$ \\ Gastão Wagner de Sousa Campos ${ }^{2}$
}

Resumo Este artigo teve como objetivo discutir as inter-relações dos relatórios das Conferências Nacionais de Saúde com as propostas apresentadas em documentos oficiais do Sistema Único de Saúde referentes à formação e desenvolvimento de recursos humanos, buscando relacioná-los à incorporação de novos referenciais pedagógicos pautados pelas metodologias ativas de ensino-aprendizagem. O estudo aqui apresentado foi do tipo exploratório, referente à pesquisa na literatura das áreas de saúde e educação, no período de 1941 - realização da $1^{\text {a }}$ Conferência Nacional de Saúde - até 2007, quando foi publicada a portaria n. 1.996 GM/MS. Essa portaria definiu novas diretrizes e estratégias para a implementação da Política Nacional de Educação Permanente em Saúde, com o objetivo de evidenciar a importância da formação de recursos humanos para a consolidação do Sistema Único de Saúde. Verificou-se que há correlação entre as reivindicações que emergem de necessidades sociais identificadas na construção do Sistema Único de Saúde e as propostas inscritas nas legislações pertinentes. Destaca-se que o sucesso de projetos de educação permanente depende de profunda imbricação entre processos educativos e de intervenção institucional, que contemplem a complexidade dos modos de fazer saúde.

Palavras-chave formação de recursos humanos em saúde; metodologias ativas; educação permanente em saúde.
Abstract The purpose of this article was to discuss the interrelations between the reports from the National Health Conferences and the proposals submitted in official Unified Health System documents regarding human resource training and development, seeking to relate them to the incorporation of new pedagogical frameworks guided by active teaching-learning methods. The study presented here was exploratory, referring to research done on the literature in the areas of health and education for the period ranging from 1941 - when the 1st National Health Conference was held - to 2007, when decree No. 1996 GM/MS. This decree was enacted setting new guidelines and strategies for the implementation of the National Policy of Continuing Education in Health, in order to highlight the importance of training human resources to consolidate the Unified Health System. It was found that there is a correlation between the claims emerging from the social needs identified in the construction of the Unified Health System and the proposals contained in the relevant legislation. It is worthy of note that the success of continuing education projects depends on the deep intertwining between educational processes and ins-titutional intervention that address the complexity of the ways of doing health.

Keywords training of human resources in health; active methodologies; continuing education in health. 


\section{Introdução}

Historicamente, tem-se investido em formação de profissionais de saúde mediante o emprego de modelos pautados pela ciência positivista com a utilização de metodologias conservadoras. Separam-se corpo e mente, razão e sentimento, ciência e ética, fragmentando-se o conhecimento e reduzindo-se o saber à busca pela eficiência técnica (Mitre et al., 2008; Figueiredo, 2012).

O paradigma de racionalidade técnica, caracterizado por modelos uniformizadores e de matriz reprodutora, com profissionais formados com base na transmissão de informações, prática repetitiva e clara separação entre teoria e prática, resulta em formação de profissionais em que predomina o exercício de prática mecanicista, individualista, acrítica e reprodutiva do trabalho em saúde (Silva e Sá-Chaves, 2008). Porém, o Sistema Único de Saúde (SUS) depende também da formação de profissionais com uma perspectiva humanista e, como tal, integradora das dimensões pessoal, social e profissional, com competências éticas, políticas e técnicas, capacidade crítica e sensibilidade para pensarem as questões da vida e da sociedade e para atuarem em contextos de incerteza e complexidade. Profissionais que sejam capazes de abordar o processo saúde-doença de maneira ampliada (Figueiredo, 2012).

Este artigo propôs a identificação das inter-relações dos relatórios das Conferências Nacionais de Saúde com as propostas apresentadas em documentos oficiais do SUS, tais como: Constituição Federal (Brasil, 1988), lei n. 8.080 (Brasil, 1990a), Política Nacional de Educação Permanente em Saúde (Brasil, 2004b) e portaria n. 1.996 (Brasil, 2007), referentes à formação e ao desenvolvimento de recursos humanos para a saúde. Buscou-se relacioná-los à incorporação de novos referenciais pedagógicos pautados pelas metodologias ativas de ensino-aprendizagem, tidas como inovadoras e com potencial indutivo de processos de formação que contribuam para a formação de profissionais cujo perfil de competência lhes permita intervir no contexto de trabalho de forma crítica, coletiva e integradora.

\section{Procedimentos metodológicos}

O estudo que deu origem a este artigo $^{3}$ foi do tipo exploratório, decorrente de pesquisa de mestrado desenvolvida no Departamento de Saúde Coletiva da Universidade Estadual de Campinas. Parte dos dados é apresentada neste texto, notadamente os da pesquisa na literatura das áreas da saúde e educação no período de 1941, quando ocorreu a I Conferência Nacional de Saúde, até 2007, quando foi publicada a portaria n. $1.996 \mathrm{GM} / \mathrm{MS}$, que definiu as novas diretrizes e estratégias para a implementação da Política Nacional de 
Educação Permanente em Saúde, adequando-a às diretrizes operacionais e ao regulamento do Pacto pela Saúde.

Com o objetivo de evidenciar a importância do tema da formação de recursos humanos para a consolidação do SUS, escolhemos analisar os relatórios das Conferências Nacionais de Saúde - principal instância nacional de manifestação dos interesses sociais e da cidadania na área da saúde (Brasil, 1990b), no que se refere à formação ou desenvolvimento de recursos humanos - e documentos oficiais identificados como reorientadores da política de formação e desenvolvimento de profissionais de saúde no SUS, particularmente a Constituição Nacional de 1988, a lei federal n. 8.080/1990, a portaria n. 198 GM/MS/2004 e a portaria GM/MS n. 1.996/2007.

A análise consistiu na identificação de como os elementos advindos das aspirações sociais manifestadas nas conferências nacionais de saúde foram incorporadas aos textos oficiais considerados.

A pesquisa foi aprovada pelo Comitê de Ética em Pesquisa da Faculdade de Ciências Médicas da Universidade Estadual de Campinas (Unicamp), parecer n. 83.964 , de 28 de agosto de 2012 , e realizada com financiamento próprio.

\section{Formação de pessoal para o SUS: bases legais}

A responsabilidade da gestão do SUS com a formação e o desenvolvimento de recursos humanos em saúde está formalizada tanto nos textos legais de institucionalização do sistema como nos relatórios das Conferências Nacionais de Saúde (Ceccim, Armani e Rocha, 2004).

Ribeiro e Motta (1996), ao discutirem a educação permanente como estratégia para a reorganização dos serviços de saúde, mostram que a preocupação com a educação no setor saúde aparece nas conferências nacionais de saúde desde suas primeiras formulações, ainda que de maneira vaga e pouco estruturada com relação às questões metodológicas, organizacionais e estratégicas. Da I à V Conferência, o tema é abordado segundo considerações gerais relativas à formação superior, principalmente de médicos e preparação de pessoal de nível técnico, com treinamento em serviço. O termo 'educação continuada' aparece pela primeira vez na VI Conferência Nacional de Saúde, em 1977, relacionado à necessidade de se manter a inclusão de novos conhecimentos na carreira de sanitarista (Ribeiro e Motta, 1996).

A VIII Conferência Nacional de Saúde, realizada em 1986 (Brasil, 1986), é considerada um marco na reformulação da Política Nacional de Saúde brasileira. Com relação à política de pessoal, foi sugerida a adoção dos seguintes princípios: capacitação e reciclagem permanente de recursos humanos e formação de profissionais de saúde integrada ao sistema regionalizado e hierarquizado de atenção à saúde. 
Com relação ao tema, a Constituição Federal de 1988 prevê no artigo 200:

Ao Sistema Único de Saúde compete, além de outras atribuições, nos termos da Lei: III - ordenar a formação de Recursos Humanos na área da saúde;

$(\ldots)$

V - incrementar em sua área de atuação o desenvolvimento científico e tecnológico (Brasil, 1988, p. 143).

A lei federal n. 8.080 (Brasil, 1990a), que dispõe sobre as condições para a promoção, proteção e recuperação da saúde, a organização e o funcionamento dos serviços, explicita a ação educacional como atribuição dos órgãos de gestão do SUS em diversos artigos $\left(6^{\circ}, 14,15,27\right.$ e 30), abrangendo aspectos relativos à:

- formulação e execução da política de formação e desenvolvimento de recursos humanos para a saúde, incluindo formulação e execução de programas que envolvam tanto a certificação/habilitação profissional quanto a educação continuada;

- realização de pesquisas e de estudos na área da saúde, com produção de conhecimentos científico e tecnológico, informações e atualização técnico-profissional;

- disponibilização dos serviços de saúde como campos para o ensino e a pesquisa - portanto, locais de ensino-aprendizagem que expressem a indissociabilidade dos papéis de gestão e formação no âmbito direto do SUS.

A lei prevê ainda a constituição de comissões permanentes com a finalidade de propor prioridades, métodos e estratégias tanto para a formação e educação continuada como para a pesquisa, além de estabelecer que essas atribuições devam ser realizadas articuladamente entre as diferentes esferas de governo e em cooperação técnica com instituições de ensino.

A IX Conferência Nacional de Saúde - realizada em 1992, a primeira após a promulgação da lei orgânica da saúde - recomenda que, para a implementação do SUS, os gestores devam assegurar uma política de formação e capacitação de recursos humanos articulada com órgãos formadores, garantir escolas de formação para os trabalhadores da saúde, destinar recursos orçamentários para desenvolvimento e formação de pessoal, criar núcleos de recursos humanos com atividades administrativas e de desenvolvimento de pessoal, além de manter e ampliar vagas para residência médica e de outros profissionais de saúde (Brasil, 1993). As recomendações da IX Conferência ressaltam que o desenvolvimento dos trabalhadores deve estar inserido na gestão de recursos humanos de cada esfera de governo, valorizando a educação voltada para o trabalho (Brasil, 1993).

Segundo Ribeiro e Motta (1996), tanto a VIII como a IX Conferência Nacional reconhecem a importância da área de recursos humanos no interior 
das políticas de saúde e convocam conferências específicas sobre o tema, que aconteceram em 1986 e 1993 - reforçando a necessidade da criação de estruturas no interior das secretarias estaduais e municipais que imprimissem um caráter permanente de investimento na formação e no desenvolvimento de pessoal para a saúde de forma descentralizada.

A X e a XI Conferência Nacional de Saúde, que ocorreram respectivamente em 1996 e 2000, foram ricas em recomendações sobre o tema, ampliando e aprofundando propostas das conferências anteriores. As propostas avançaram no sentido da instituição de mecanismos de consolidação da política de desenvolvimento e formação de pessoal por meio de estratégias como: reforçar a estreita relação entre processo formativo e processo de trabalho em saúde, de modo a valorizar a formação de profissionais mediante as necessidades concretas de saúde da população; consolidar investimentos financeiros com repasses específicos para essas atividades, inclusive instando as secretarias de Saúde estaduais e municipais a manter técnica e financeiramente escolas de formação, com autonomia e integradas aos respectivos conselhos de saúde, bem como às respectivas secretarias de Educação e às universidades - privilegiadamente as universidades estaduais. A articulação dos serviços de saúde com os aparelhos formadores e os mecanismos de controle social do SUS reaparece com riqueza de proposições (Brasil, 1998, 2000).

Surgiram novas propostas, como a recomendação da revisão das diretrizes curriculares para formação em saúde, adequando-as às realidades locais e regionais, aos avanços tecnológicos, às necessidades epidemiológicas e às demandas quantitativas e qualitativas do SUS, além da definição de critérios rígidos para o estabelecimento de novas instituições formadoras, bem como a avaliação da qualidade dos cursos. Em 2001, foi emitido o parecer n. CNE/CES 1.133/2001 do Conselho Nacional de Educação (Brasil, 2001) para várias profissões de saúde, com definição de diretrizes nacionais curriculares, valorizando a formação generalista, humanista, crítica e reflexiva. Afirmava ainda a importância do conceito de saúde coletiva e os princípios e diretrizes do SUS na formação. As novas diretrizes para os cursos da área adotaram, entre seus documentos de referência, o relatório da XI Conferência Nacional de Saúde.

Com relação à pós-graduação, incentivou-se o aumento de vagas para residências médicas e multiprofissionais, direcionando a abertura de vagas e condicionando-as às necessidades de saúde da população e às especificidades regionais. Pela primeira vez em relatórios de conferências nacionais, enfatizaram-se a formação de gerentes com capacitação em administração pública e a garantia de capacitação específica na gestão de recursos humanos.

A preocupação com a graduação e com a habilitação formal gerou mudanças curriculares e programas de apoio à qualificação da formação, como o Programa de Reorientação da Formação Profissional em Saúde (Pró-Saúde), 
para incentivar transformações do processo de formação, geração de conhecimentos e prestação de serviços à comunidade, numa abordagem integral do processo de saúde-doença (Brasil, 2005). Destaque-se também o Programa de Educação pelo Trabalho para a Saúde (PET-Saúde), que teve como pressuposto a educação por meio do trabalho, caracterizando-se como instrumento para qualificação em serviço dos profissionais da área, bem como de iniciação ao trabalho tendo em perspectiva a inserção das necessidades dos serviços como fonte de produção de conhecimento e pesquisa nas instituições de ensino (Brasil, 2010).

A XII Conferência Nacional de Saúde, inicialmente programada para ser realizada em 2004, foi antecipada para dezembro de 2003, por iniciativa do então ministro da Saúde, Humberto Costa, com a finalidade de produzir orientações para a formulação do Plano Nacional de Saúde. Essa alteração veio no bojo da mudança política nacional marcada pela posse do então presidente Luiz Inácio Lula da Silva e de sua equipe em janeiro de 2003. Segundo o relatório da XII Conferência Nacional de Saúde, “a participação popular no governo federal deixou de ser mera formalidade, tornou-se uma ação política concreta" (Brasil, 2004a). Nesta conferência nacional, sem negar os avanços apontados pelas anteriores, a gestão da educação aparecia estreitamente vinculada à necessidade de mudança no modelo de atenção à saúde, enfatizando a interdependência entre a qualidade da assistência prestada e a adesão e qualidade do trabalho do profissional de saúde - a qual depende das condições de trabalho e da capacitação para seu exercício. Nesse sentido, as propostas foram apresentadas segundo os seguintes eixos: Regularização dos Vínculos e Desprecarização do Trabalho em Saúde; Relações de Trabalho e Saúde do Trabalhador da Saúde; Formação dos Profissionais de Saúde; e Gestão da Educação em Saúde e Educação Permanente e Educação em Serviço, com recomendações exaustivas em todos os eixos considerados (Brasil, 2004a).

Com relação à gestão da educação em saúde e à educação permanente, a XII Conferência enfatizou a ação das secretarias estaduais e municipais de Saúde no sentido de implementarem articuladamente uma política de programas de educação permanente, com ênfase nos princípios da intersetorialidade e com equipes multiprofissionais para romper a formação fragmentada e reafirmar os princípios do SUS.

Dentre as numerosas recomendações, destacamos algumas proposições que julgamos ter relação direta com a nova política de formação e desenvolvimento de trabalhadores do setor saúde que seria lançada no ano seguinte e que proporia a inversão da lógica de ensino-aprendizagem que vinha sendo professada até o momento e da qual trataremos adiante. São elas: o incentivo às instituições de ensino superior em saúde que busquem implantação de novas metodologias de ensino, as quais visem à formação de profissionais voltados para a prática multiprofissional segundo os interesses e necessi- 
dades da população; a implantação de polos de educação permanente em saúde em todos os estados, com o objetivo de discutir e implementar projetos de mudança do ensino formal, de educação permanente, formação técnica, graduação e pós-graduação dos trabalhadores e gestores, para que atendam às necessidades de saúde da população e aos princípios e diretrizes do SUS; a modificação do modelo de formação dos profissionais, hoje centrado na atenção à doença; e a diversificação dos cenários de prática na formação, com a garantia de que no mínimo $50 \%$ das residências acadêmicas e dos estágios curriculares da área sejam feitos no âmbito da atenção básica.

Em 2004, o Ministério da Saúde instituiu, por meio da portaria n. 198 GM/MS, a Política Nacional de Educação Permanente em Saúde como estratégia do SUS para a formação e o desenvolvimento de trabalhadores do setor (Brasil, 2004b). Pela portaria, a política deveria ser efetivada pelos polos de educação permanente, instância interinstitucional e locorregional com a função de identificar as necessidades de formação e desenvolvimento dos trabalhadores do setor saúde, além de construir estratégias e processos que qualificassem a atenção e a gestão e fortalecessem o controle social.

O lançamento da portaria n. 198 desencadeou um processo de construção coletiva de uma política de educação permanente para o SUS, representando grande avanço no sentido de inverter a lógica de oferta de formação e desenvolvimento antes consolidada com o envio de pacotes de curso e treinamentos (Organização Pan-Americana da Saúde, 2005; Figueiredo, 2012). Em um ano, foram constituídos 96 polos de educação permanente no país (Organização Pan-Americana da Saúde, 2005). No entanto, ao mesmo tempo que se registraram várias experiências exitosas de articulação da educação à gestão para a reformulação das práticas, muitos limites e dificuldades se apresentaram em relação à estruturação e ao funcionamento dessa política. A capilarização dos polos foi desigual nas diversas regiões do país, principalmente pela dificuldade na pactuação entre instituições formadoras, gestores e serviços (Figueiredo, 2012).

Em agosto de 2007, o Ministério da Saúde publicou a portaria GM/MS n. 1.996 (Brasil, 2007), que definiu novas diretrizes e estratégias para a implementação da Política Nacional de Educação Permanente, adequando-as às diretrizes regionais e ao regulamento do Pacto pela Saúde. Na nova formulação, a condução regional da Política Nacional de Educação Permanente em Saúde se daria por meio dos Colegiados de Gestão Regional (CGRs), 4 com o apoio das Comissões Permanentes de Integração Ensino-Serviço (CIESs), como previsto na mesma portaria GM/MS n. 1.996 (Brasil, 2007). As CIESs são instâncias intersetoriais e interinstitucionais permanentes que participam da formulação, da condução e do desenvolvimento da Política de Educação em Saúde. A portaria reforçou o conceito de educação permanente como prática educativa, ancorada no trabalho e no conhecimento prévio 
dos trabalhadores, na problematização da realidade, na aprendizagem significativa e na transformação da prática. Sugeriu-se que tais estratégias fossem construídas de maneira pactuada, com o envolvimento de atores tanto do setor saúde (gestores, trabalhadores e usuários) como da educação (gestores, instituições de ensino, estudantes de cursos da área da saúde).

Como vimos, nos textos governamentais existe a preocupação com a educação formal, que gera habilitação profissional específica, e com o desenvolvimento dos profissionais já habilitados e inseridos no mundo do trabalho. O desenvolvimento destes profissionais aparece nos textos oficiais com diferentes designações, como treinamento, reciclagem, educação contínua ou continuada, capacitação, educação permanente ou aperfeiçoamento, entre outras. Tais denominações, embora se refiram às práticas educativas para o trabalhador inserido no serviço, apresentam diferenciações metodológicas que refletem uma diferença de conceituação sobre o processo de ensino-aprendizagem.

Essa breve passagem sobre as informações constantes nas legislações do SUS e nas Conferências Nacionais de Saúde sobre desenvolvimento e formação de recursos humanos para a saúde indica o crescimento da importância do assunto para a consolidação do SUS.

\section{Mudança na lógica da formação: a educação permanente em saúde e a democratização da gestão}

No setor saúde, tradicionalmente produzem-se programas de ação ou ações programáticas em função de políticas específicas com base em áreas técnicas especializadas. Cada programa gera uma linha de capacitações em que se prescreve a suposta melhor prática de saúde. Tais capacitações não se mostram eficazes para possibilitar a incorporação de novos conceitos e princípios às práticas estabelecidas, por trabalharem de maneira descontextualizada e se basearem principalmente na transmissão de conhecimentos (Ceccim, 2005). Mesmo após a reformulação das políticas de educação permanente pelo Ministério da Saúde, essas antigas práticas permaneceram, verificando-se, na realidade, uma mistura de várias estratégias de formação.

Parece-nos importante fazer uma breve diferenciação de dois termos frequentemente usados quando se trata de formação em serviço: educação continuada e educação permanente. Embora os dois termos confiram uma dimensão temporal de continuidade do processo de formação durante a vida profissional, designam princípios metodológicos diversos.

Segundo Ribeiro e Motta (1996), a educação continuada, em geral, se inscreve como prática educativa tradicional. Vem em resposta às demandas de serviço e profissionais de recuperar conhecimentos e habilidades esque- 
cidas, assim como de acompanhar as mudanças trazidas pelo progresso científico tecnológico a fim de melhorar o desempenho profissional. Assenta-se na concepção de que a aquisição de mais informações pode melhorar a competência dos profissionais para desenvolver suas responsabilidades; aposta no enfoque disciplinar e geralmente é direcionada para uma única categoria profissional; adota o modelo pedagógico centrado na transmissão de conhecimento realizado geralmente fora do espaço de trabalho - onde, em geral, se prescreve uma prática idealizada que, embora traga uma contribuição importante para a formação profissional, geralmente não cumpre a necessidade de transformação das práticas institucionais.

Em seus cursos de atualização, os profissionais são elevados ao paraíso do 'como deveria ser', tradução da verdade do conhecimento científico acumulado e atualizado, aplicável numa espécie de representação universal e única de pacientes e serviços. Quando retornam aos serviços, entretanto, se veem confrontados em suas realidades cotidianas com a impossibilidade da aplicação do conhecimento adquirido. Na prática, a teoria é outra. “O curso foi ótimo, os serviços é que não oferecem condições para o nosso trabalho, são frustrantes" (Ribeiro e Motta, 1996, p. 3).

Tais práticas educativas não conseguem responder às características dinâmicas e incertas do contexto, que exigem profissionais críticos e competentes para assumir a complexidade do cuidar em saúde.

Mitre e colaboradores (2008), ao discutirem metodologias ativas de ensino-aprendizagem na formação do profissional de saúde, observam que as profundas modificações no mundo contemporâneo - como a velocidade das transformações sociais, a da produção de conhecimento, a influência dos meios de comunicação na formação dos profissionais e a possibilidade atual de relativização de valores até então considerados intocáveis - nos apresentam o desafio de desenvolver a autonomia individual e coletiva com a busca de métodos inovadores:

A educação deve ser capaz de desencadear uma visão do todo - de interdependência e de transdisciplinaridade - além de possibilitar a construção de redes sociais, com a consequente expansão da consciência individual e coletiva. Portanto, um dos seus méritos está, justamente, na crescente tendência à busca de métodos inovadores, que admitam uma prática pedagógica ética, crítica, reflexiva e transformadora, ultrapassando os limites do treinamento puramente técnico, para efetivamente alcançar a formação do homem como um ser histórico, inscrito na dialética da ação-reflexão-ação (Mitre et al., 2008, p. 2.134).

Berbel (2011), ao conceituar metodologias ativas, entende que são metodologias baseadas em formas de desenvolver o processo de aprender, utilizando 
experiências reais ou simuladas, visando às condições de solucionar com sucesso desafios advindos das atividades essenciais da prática social, em diferentes contextos, alicerçadas no princípio da autonomia do educando. A autora encontra em Paulo Freire uma defesa para as metodologias ativas, sustentando que na educação de adultos o que impulsiona a aprendizagem é a resolução de problemas e a construção do conhecimento novo mediante conhecimentos e experiências prévias dos indivíduos (Berbel, 2011).

Nesse cenário, a educação permanente em saúde surge como possibilidade de prática educativa inovadora. Propõe incorporar o ensino-aprendizagem no cotidiano dos serviços de saúde, modificando estratégias educativas nas quais o processo de trabalho é revalorizado como centro privilegiado da aprendizagem e o profissional como ator reflexivo e construtor de saber (Ribeiro e Motta, 1996; Figueiredo, 2012).

No anexo II da portaria GM/MS n. 198/2004 (Brasil, 2004b), que trata da operacionalização da educação permanente, o Ministério da Saúde a define como:

A Educação Permanente é aprendizagem no trabalho, onde o aprender e o ensinar se incorporam ao quotidiano das organizações e ao trabalho. Propõe-se que os processos de capacitação dos trabalhadores da saúde tomem como referência as necessidades de saúde das pessoas e das populações, da gestão setorial e do controle social em saúde, tenham como objetivos a transformação das práticas profissionais e da própria organização do trabalho e sejam estruturados a partir da problematização do processo de trabalho (Brasil, 2004b, p. 38).

O reconhecimento da necessidade do setor saúde de investir em um processo educativo que incorpore as práticas cotidianas - tomando-as como um processo a ser analisado e transformado, na busca de qualificação da gestão/atenção/ensino, e que inclua ativamente os atores neles implicados é preocupação de diversos autores. Ceccim, em texto onde ressalta o desafio que é a educação permanente para o setor saúde, afirma:

Além da velocidade com que conhecimentos e saberes tecnológicos se renovam na área da saúde, a distribuição de profissionais e de serviços segundo o princípio da acessibilidade para o conjunto da população o mais próximo de sua moradia ou de onde procuram por atendimento - faz com que se torne muito complexa a atualização permanente dos trabalhadores. Torna-se crucial o desenvolvimento de recursos tecnológicos de operação do trabalho perfilados pela noção de aprender a aprender, de trabalhar em equipe, de construir cotidianos eles mesmos como objeto de aprendizagem individual, coletiva e institucional (Ceccim, 2005, p. 163).

Além de uma política pública, a educação permanente em saúde é uma prática de ensino-aprendizagem que incorpora elementos das metodologias 
educacionais ativas. Como prática, apoia-se no conceito de ensino problematizador, com produção de conhecimento mediante análise crítica do cotidiano, horizontalidade entre educador e educando, prática dialógica e o conceito de 'aprendizagem significativa', que se caracteriza pela interação cognitiva do conhecimento novo com os conhecimentos prévios dos educandos (Ceccim e Ferla, 2008; Moreira e Masini, 2006).

A educação permanente como uma política nacional afirma a articulação entre ensino, trabalho e cidadania, a vinculação entre formação, gestão, atenção e participação social, a construção da rede do SUS como espaço de educação profissional e o reconhecimento de bases locorregionais em que estruturas de ensino e serviço formulam, conjuntamente, estratégias de ensino (Ceccim, Armani e Rocha, 2004; Ceccim e Ferla, 2008). Nesse sentido, a proposta confia na construção de espaços coletivos de cogestão para viabilizá-la.

Desse ponto de vista, o gestor federal, proponente da educação permanente em saúde para o SUS, desencadeou um processo de constituição de uma gestão colegiada da educação permanente em saúde. Para o gestor federal do SUS, uma articulação interinstitucional para a educação permanente em saúde, com uma gestão colegiada, quebra a regra da verticalidade única e hierarquizada nos fluxos organizativos. Também supera a racionalidade gerencial hegemônica e a tradicional concepção educativa dos treinamentos para pessoal de serviço (Ceccim e Feuerwerker, 2004, p. 55).

Figueiredo (2012, p. 98), ao abordar a formação com instância de mobilização do sujeito e do trabalho em saúde, ressalta que o ensino problematizador visa produzir uma postura ativa na construção do conhecimento, destacando que o sucesso de projetos de educação permanente "dependem de uma profunda imbricação entre processos educativos e processos de intervenção institucional, que contemplem a complexidade dos vetores que incidem na coprodução dos modos de fazer saúde".

A premissa da Política Nacional de Educação Permanente de contribuir com a democratização das práticas pedagógicas está em consonância com a proposta apresentada por Campos (2007) em Um método para análise e cogestão de coletivos (ou método da roda), que propõe um modo diferente de fazer gestão, o qual privilegia o envolvimento dos sujeitos implicados com um determinado processo de trabalho. Assim, altera o modo tradicional de fazer gestão de 'intervir SOBRE' para 'intervir COM'. Propõe a ampliação do conceito de trabalho, um trabalho que supere a concepção restrita de trabalho produtivo e seja visto também como um dos caminhos necessários à própria constituição do sujeito. Nesse sentido, considera o trabalho com uma tripla finalidade: produção de bens ou serviços, reprodução da própria organização e interferência na produção social e subjetiva dos trabalhadores 
e dos usuários. O método ressalta o fortalecimento do sujeito e a construção da democracia institucional.

A cogestão, realizada em Espaços Coletivos, é um caminho para a democratização e para a progressiva desalienação da maioria. A desalienação absoluta é uma utopia, o Método da Roda aposta na possibilidade de se instituírem sistemas de cogestão que produzam tanto compromisso e solidariedade com o interesse público, quanto capacidade reflexiva e autonomia dos agentes da produção. A construção e o funcionamento dos Espaços Coletivos considerados uma questão metodológica. A produção e funcionamento de espaços coletivos: a roda (Campos, 2007, p. 28).

Ao adotar essa perspectiva, Campos (2007) se contrapõe às práticas gerenciais hegemônicas, legado do taylorismo, que entende a gestão separada da prática. Tal perspectiva é baseada na disciplina, no controle e na concentração de poder. Advoga a separação entre o trabalho intelectual de quem planeja (dirigente) do momento da execução (dos trabalhadores). Os trabalhadores são treinados para obedecer a ordens, executar normas e rotinas, realizar tarefas repetidas e seriadas, geralmente fragmentadas, que não deixam transparecer o processo de trabalho como um todo. São expropriados da capacidade de pensar e agir sobre seu trabalho, alienados de todo o processo. A relação é vertical e exige supervisão constante.

Ao discutir o eixo de conformação do 'método da roda', Campos (2007) demonstra que, apesar das numerosas inovações introduzidas nos processos de trabalho no último século, o taylorismo não foi superado.

Um dos achados desta investigação é que o taylorismo, ainda que bastante alterado depois do advento da sociologia das organizações, da qualidade total e do envolvimento de certa psicologia com a administração de pessoal, continua central para a compreensão do que se poderia denominar de Racionalidade Gerencial Hegemônica. Neste sentido, não foi ainda superado e sua lógica de controle social e de redução do trabalhador à condição de coisa tem sido, ao longo do século XX, o método responsável pela transformação da Alienação formal em Alienação real (Campos, 2007, p. 26).

A Política Nacional de Educação Permanente proposta pelo Ministério da Saúde possibilitou a construção e a institucionalização de espaços coletivos, em que é possível se analisar a prática cotidiana no setor saúde, no sentido de transformá-la, qualificando-a. Entretanto, esses processos de educação permanente não necessariamente logram incluir ativamente os trabalhadores e usuários em espaços coletivos de cogestão.

Permanecem como constante possibilidade de campo investigativo as formas segundo as quais as organizações de saúde têm incorporado e desen- 
volvido os processos de educação permanente - isto é, qual modelagem realizada, por quem, com quais objetivos; quais os caminhos percorridos pelos processos de educação permanente; qual o potencial de capilarização dos processos concretizados; e em que medida a educação permanente em saúde se mostra potente para transformar a prática do trabalho em saúde no sentido da qualificação da atenção e da democratização de gestão.

\section{Considerações finais}

Ao se buscar evidenciar as relações entre as propostas inscritas nos relatórios das conferências nacionais de saúde com a conformação expressa dos documentos oficiais em relação à formação e ao desenvolvimento de recursos humanos para a saúde, é possível indicar que há correlação entre as reivindicações que emergem dos interesses sociais e as propostas inscritas nas legislações pertinentes, indicando o crescimento da importância do assunto para a consolidação do SUS

A Política Nacional de Educação Permanente em Saúde enfatiza a necessidade de alteração de ordem metodológica nos processos de formação em saúde. Ao explicitar princípios pedagógicos como a aprendizagem significativa, o processo de aprender a aprender e a eleição dos problemas do cotidiano como fonte de aprendizagem, se inscreve na lógica das metodologias ativas de ensino-aprendizagem, como referenciais pedagógicos inovadores e necessários para a promoção de mudanças visando às práticas integradoras e democráticas.

Os processos educativos propostos estão imersos em contexto complexo, com práticas gestoras e de cuidado nem sempre inclusivas e democráticas. Em instituições em que o taylorismo ainda não foi superado e permanece a lógica da racionalidade gerencial hegemônica, desenvolver práticas educativas promotoras de autonomia e inclusão do sujeito torna-se um desafio (Campos, 2007).

Ao se considerar tanto o desenvolvimento do SUS como o dos processos educativos, vale enfatizar a importância de se investir em pesquisas de acompanhamento da implantação/implementação de atividades educativas na lógica proposta pela Política Nacional de Educação Permanente, verificando como as instituições que se propõem esse desafio têm enfrentado os obstáculos pertinentes ao processo de transformação. 


\section{Colaboradores}

Os autores participaram igualmente de todas as etapas de elaboração deste artigo.

Resumen Este artículo tuvo como objetivo discutir las interrelaciones de los informes de las Conferencias Nacionales de Salud con las propuestas presentadas en documentos oficiales del Sistema Único de Salud referentes a la formación y desarrollo de recursos humanos, buscando relacionarlas a la incorporación de nuevas referencias pedagógicas orientadas por las metodologías activas de enseñanza-aprendizaje. El estudio aquí presentado fue de tipo exploratorio, basado en investigación en la literatura de las áreas de salud y educación, en el período de 1941 de la $1^{\text {a }}$ Conferencia Nacional de Salud - hasta 2007, cuando se publicó la ordenanza n 1.996 GM/MS. Esta definió nuevas directrices y estrategias para la implementación de la Política Nacional de Educación Permanente en Salud, con el objetivo de destacar la importancia de la formación de recursos humanos para la consolidación del Sistema Único de Salud. Se observó que hay una correlación entre las reivindicaciones que emergen de necesidades sociales identificadas en la construcción del Sistema Único de Salud y las propuestas inscritas en las legislaciones pertinentes. Se destaca que el éxito de proyectos de educación permanente depende de un profundo entramado entre procesos educativos y de intervención institucional, que contemplen la complejidad de los modos de hacer salud.

Palabras clave formación de recursos humanos en salud; metodologías activas; educación permanente en salud.

\section{Notas}

${ }^{1}$ Hospital Municipal Dr. Mário Gatti, Campinas, São Paulo, Brasil.

$<$ renatagigante@ig.com.br>

Correspondência: Avenida Prefeito Faria Lima, 340, Parque Itália, CEP 13036-220, Campinas, São Paulo, Brasil.

2 Universidade Estadual de Campinas, Faculdade de Ciências Médicas, Departamento de Saúde Coletiva, Campinas, São Paulo, Brasil.

<gastaowagner@mpc.com.br>

${ }^{3}$ Este artigo é parte da dissertação de mestrado intitulada Educação Permanente em Saúde para gestores: qualificação do cuidado e gestão democrática, de autoria de Renata Lúcia Gigante, apresentada à Comissão de Pós-Graduação em Saúde Coletiva da Faculdade de Ciências Médicas da Unicamp, para obtenção do título de Mestre em Saúde Coletiva na área de concentração Política, Planejamento e Gestão em Saúde. 
4 Colegiado de Gestão Regional é um espaço de articulação e pactuação, correspondente a uma região de saúde, que se constitui como instância capaz de gerar novas possibilidades de gestão no âmbito do SUS, com potencialidade para qualificar e diferenciar o processo de regionalização da saúde. Para saber mais, consultar <http://bvsms.saude. gov.br/bvs/saudelegis/gm/2006/prt0399_22_02_2006.html>.

\section{Referências}

BERBEL, Neusi A. N. As metodologias ativas e a promoção da autonomia de estudantes. Semina: Ciências Sociais e Humanas, Londrina, v. 32, n. 1, p. 25-40, 2011.

BRASIL. Ministério da Saúde. Conselho Nacional de Saúde. CONFERÊNCIA NACIONAL DE SAÚDE: REFORMULAÇÃO DO SISTEMA NACIONAL DE SAÚDE, 8. Relatório final. Brasília: Ministério da Saúde, 1986. Disponível em: <http://conselho.saude.gov.br/ biblioteca/Relatorios/relatorio_8.pdf $>$. Acesso em: 16 jun. 2016.

BRASIL. Constituição da República Federativa do Brasil. Diário Oficial da República Federativa do Brasil, Brasília, 5 jan. 1988. p. 1, anexo. Disponível em: <www.tse.jus.br/ legislacao/codigo-eleitoral/constituicaofederal/constituicao-da-republica-federativado-brasil>. Acesso em: 16 jun. 2016.

BRASIL. Lei n. 8.080, de 19 de setembro de 1990a. Dispõe sobre as condições para a promoção, proteção e recuperação da saúde, a organização e o funcionamento dos serviços correspondentes e dá outras providências. Diário Oficial da República Federativa do Brasil, Brasília, 20 set. 1990. Seção 1, p. 18.055.

BRASIL. Lei n. 8.142, de 28 de dezembro de 1990b. Dispõe sobre a participação da comunidade na gestão do Sistema Único de Saúde (SUS) e sobre as transferências intergovernamentais de recursos financeiros na área da saúde e dá outras providências. Diário Oficial da República Federativa do Brasil, Brasília, 31 dez. 1990. Seção 1, p. 25.694.
BRASIL. Ministério da Saúde. Conselho Nacional de Saúde. CONFERÊNCIA NACIONAL DE SAÚDE: SAÚDE - MUNICIPALIZAÇÃO É O CAMINHO, 9. Relatório final. Brasília: Ministério da Saúde, 1993. Disponível em: $<$ http://conselho.saude.gov.br/biblioteca/ Relatorios/relatorio_9.pdf $>$. Acesso em: 16 jun. 2016 .

BRASIL. Ministério da Saúde. Conselho Nacional de Saúde. CONFERÊNCIA NACIONAL DE SAÚDE: ONDE DÁ SUS, DÁ CERTO!, 10. Relatório final. Brasília: Ministério da Saúde, 1998. Disponível em: <http://conselho.saude. gov.br/biblioteca/Relatorios/relatorio_10.pdf >. Acesso em 16 jun. 2016.

BRASIL. Ministério da Saúde. Conselho Nacional de Saúde. CONFERÊNCIA NACIONAL DE SAÚDE: EFETIVANDO O SUS - ACESSO, QUALIDADE E HUMANIZAÇÃO NA ATENÇÃO À SAÚDE, COM CONTROLE SOCIAL, 11. Relatório final. Brasília: Ministério da Saúde, 2000 (Série D. Reuniões e Conferências, n. 16). Disponível em: <http://conselho. saude.gov.br/biblioteca/Relatorios/relatorio_ 11.pdf>. Acesso em 16 jun. 2016.

BRASIL. Ministério da Educação. Parecer n. CNE/CES 1.133, de 3 de outubro de 2001. Diretrizes curriculares nacionais dos cursos de graduação em enfermagem, medicina e nutrição. Diário Oficial da República Federativa do Brasil, Brasília, 3 out. 2001. Seção 1E, p. 131.

BRASIL. Ministério da Saúde. Conselho Nacional de Saúde. CONFERÊNCIA NACIONAL 
DE SAÚDE. CONFERÊNCIA SERGIO AROUCA: SAÚDE, UM DIREITO DE TODOS E UM DEVER DO ESTADO - A SAÚDE QUE TEMOS, O SUS QUE QUEREMOS, 12. Relatório final. Brasília: Ministério da Saúde, 2004a (Série D. Reuniões e Conferências). Disponível em: $<$ http://conselho.saude.gov.br/biblioteca/ Relatorios/relatorio_12.pdf>. Acesso em 16 jun. 2016.

BRASIL. Portaria n. 198 GM/MS, de 13 de fevereiro de 2004b. Política Nacional de Educação Permanente em Saúde. Diário Oficial da República Federativa do Brasil, Brasília, 16 fev. 2004. Seção 1, p. 37-41.

BRASIL. Portaria interministerial n. 2.101, de 3 de novembro de 2005. Programa Nacional de Reorientação da Formação Profissional em Saúde - Pró-Saúde. Diário Oficial da República Federativa do Brasil, Brasília, 4 nov. 2005. Seção 1, p. 111.

BRASIL. Portaria n. 1.996 GM/MS, de 20 de agosto de 2007. Política Nacional de Educação Permanente em Saúde. Diário Oficial da República Federativa do Brasil, Brasília, 22 ago. 2007. Seção 1, p. 34.

BRASIL. Portaria interministerial n. 421, de 3 de março de 2010. Programa de Educação pelo Trabalho para a Saúde - PET-Saúde. Diário Oficial da República Federativa do Brasil, Brasília, 5 mar. 2010. Seção 1, p. 52.

CAMPOS, Gastão W. S. Um método para análise e cogestão de coletivos. 3. ed. São Paulo: Hucitec, 2007.

CECCIM, Ricardo B. Educação permanente em saúde: desafio ambicioso e necessário. Interface: Comunicação, Saúde, Educação, Botucatu, v. 9, n. 16, p. 161-177, set.2004/fev.2005.

CECCIM, Ricardo B.; ARMANI, Teresa B.; ROCHA, Cristiane. F. O que dizem a legislação e o controle social em saúde sobre a formação de recursos humanos e o papel dos gestores públicos no Brasil. In: BRASIL. Ministério da Saúde. Secretaria de Gestão do Trabalho e da Educação na Saúde. Departamento de Gestão da Educação na Saúde. SUS Brasil: cadernos de textos. Brasília: Ministério da Saúde, 2004 (Série B. Textos Básicos de Saúde). p. 156-175.

CECCIM, Ricardo B.; FERLA, Alcindo A. Educação permanente em saúde. In: PEREIRA, Isabel B.; LIMA, Julio C. F (orgs.). Dicionário da educação profissional em saúde. 2. ed. rev. ampl. Rio de Janeiro: EPSJV, 2008. p. 162-168.

CECCIM, Ricardo B.; FEUERWERKER, Laura. O quadrilátero da formação para a área da saúde: ensino, gestão, atenção e controle social. Physis: Revista de Saúde Coletiva, Rio de Janeiro, v. 14, n. 1, p. 41-65, 2004.

FIGUEIREDO, Mariana D. A construção de práticas ampliadas e compartilhadas em saúde: apoio Paideia e formação. Tese (Doutorado em Saúde Coletiva) - Faculdade de Ciências Médicas, Universidade Estadual de Campinas, Campinas, 2012.

GIGANTE, Renata L. Educação Permanente em Saúde para gestores: qualificação do cuidado e gestão democrática. 131. fls. Dissertação (Mestrado em Saúde Coletiva) - Faculdade de Ciências Médicas, Universidade Estadual de Campinas, Campinas, 2014. Disponível em: <www.bibliotecadigital.unicamp.br/ document $/$ ? code $=000931546 \&$ opt $=4>$. Acesso em: 14 jun. 2016

MITRE, Sandra M. et al. Metodologias ativas de ensino-aprendizagem na formação profissional em saúde: debates atuais. Ciência \& Saúde Coletiva, Rio de Janeiro, v. 13, supl. 2, p. 2.133-2.144, 2008.

MOREIRA, Marco A.; MASINI, Elcie A. S. Aprendizagem significativa: a teoria de aprendizagem de David Ausubel. 2. ed. São Paulo: Centauro, 2006.

ORGANIZAÇÃO PAN-AMERICANA DA SAÚDE (OPAS). Conversando sobre os polos de educação permanente. s/d. Disponível em: <www. paho.org/bra/index.php?option $=$ com docman\&task $=$ doc_view \&gid $=562 \&$ Itemid=423>. Acesso em: 15 jun. 2016.

RIBEIRO, Eliana C. O.; MOTTA, José I. J. Educação permanente como estratégia na 
reorganização dos serviços de saúde. Divulgação em Saúde para Debate, Londrina, v. 12, p. 39-44, 1996.

SILVA, Roseli F.; SÁ-CHAVES, Idália. Formação reflexiva: representações dos professores acerca do uso de portfólio reflexivo na formação de médicos e enfermeiros. Interface: Comunicação, Saúde, Educação, Botucatu, v. 12, n. 27, p. 721-734, 2008.

Recebido em 06/12/2013

Aprovado em 31/03/2015 